\title{
Effect of an Empowerment Program on Self-Efficacy of Epileptic Child's Mothers in Psychological Adaptation, Gaining Support and Receiving Information
}

\author{
Gholami S.* MSc, Reyhani T. ${ }^{1}$ MSc, Beiraghi Toosi M. ${ }^{2}$ PhD, Behnam Vashani H. ${ }^{3}$ MSc
}

\begin{abstract}
*Operating Room Department, Nursing \& Midwifery School, North Khorasan University of Medical Sciences, Bojnurd, Iran

1Pediatric \& Infant Department, Nursing \& Midwifery School, Mashhad University of Medical Sciences, Mashhad, Iran

2Pediatric Department, Medicine School, Mashhad University of Medical Sciences, Mashhad, Iran

3Pediatric \& Infant Department, Nursing \& Midwifery School, Mashhad University of Medical Sciences, Mashhad, Iran
\end{abstract}

\begin{abstract}
Aims: Epilepsy is one of the most prevalent childhood neurological disorders. As the primary caregivers, the mothers of epileptic children undergo different psychological pressures. The aim of the study was to investigate the effects of empowerment on the self-efficacy of the mothers of the epileptic children, concerning psychological adaptation, gaining support, and receiving information.

Materials \& Methods: In the controlled two-group random clinical trial with pretest and posttest steps, 100 mothers of epileptic children hospitalized in the Neurology Ward of Ghaem Hospital of Mashhad were studied in 2014. The subjects, selected via convenience sampling method, were randomly divided into two groups including experimental $(n=50)$ and control $(n=50)$ groups. Data was collected using the caregiver's self-efficacy questionnaire. Only experimental group received the empowerment program, and no intervention was conducted in control group. The mothers' self-efficacy was measured before and after the intervention in both groups. Data was analyzed by SPSS 11.5 software using independent T, paired T, Chi-square, Fisher's exact, and covariance tests.

Findings: The mean scores of self-efficacy, including psychological adjustment, gain a support, and receiving information, were not significantly different between the groups before the intervention ( $p>0.05)$. Nevertheless, the groups were significantly different after the intervention $(p<0.001)$. In addition, the mean score after the intervention in experimental group was significantly higher than the score in the same group before the intervention $(p<0.001)$.

Conclusion: The empowerment program enhances the self-efficacy of the mothers of the epileptic children in psychological adjustment, gain a support, and receiving information.
\end{abstract}

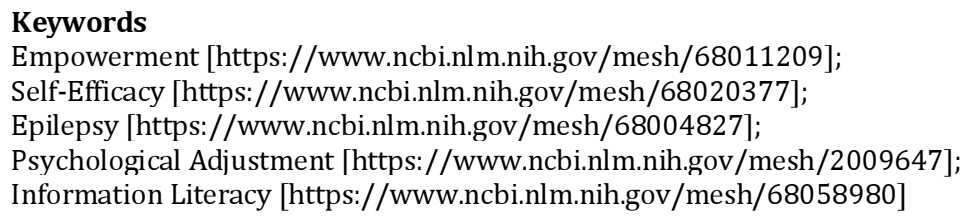

* Corresponding Author

Tel: +98 (58) 32297097

Fax: +98 (58) 32297095

Address: Nursing \& Midwifery School, North Khorasan University of Medical Sciences, Shahriyar Street, Bojnurd, Iran

gholamis921@mums.ac.ir

Received: September 29, $2015 \quad$ Accepted: August 1, $2016 \quad$ ePublished: October 1, 2016 


\section{مقدمه}

بيمارى صرع، از شايعترين اختلالات عصبى [1] و و علل ناتوانى و

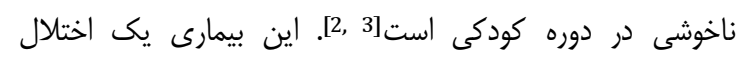

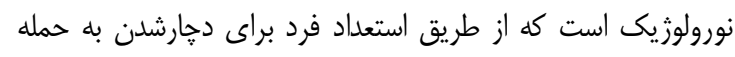

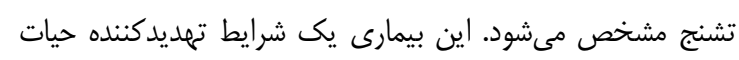

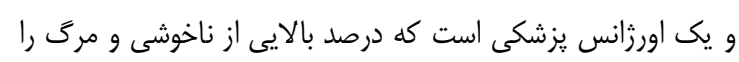

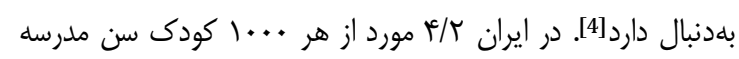

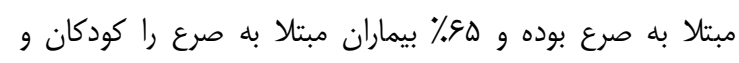

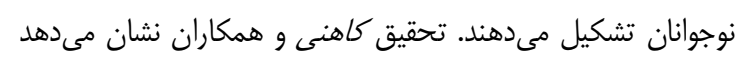

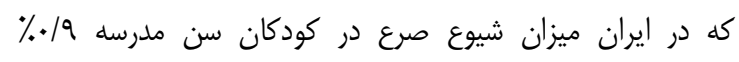
است[5]. خودكارآمدى קإيين از جمله مشكلاتى است كه مادران كودكان

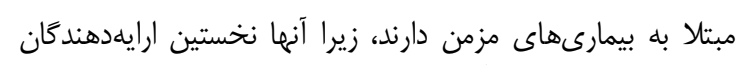

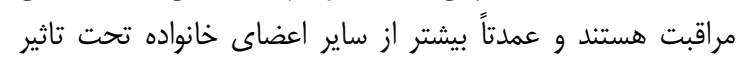

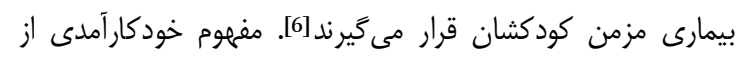

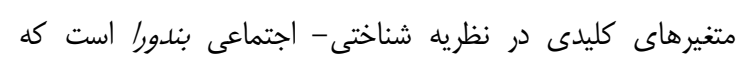

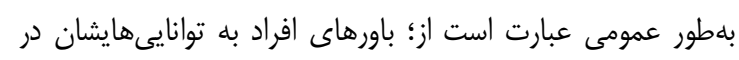

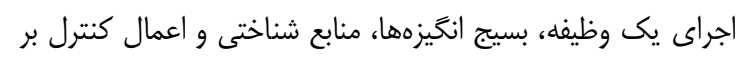

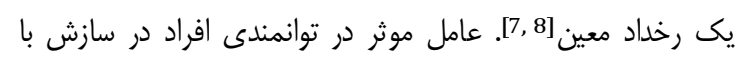

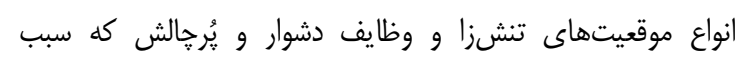

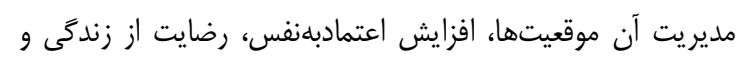

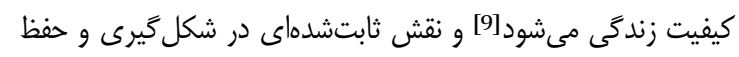

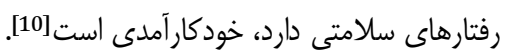

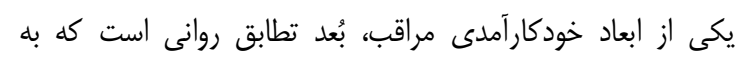

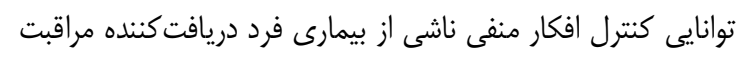

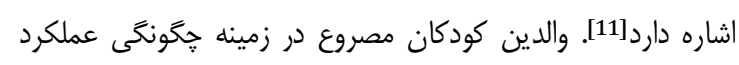

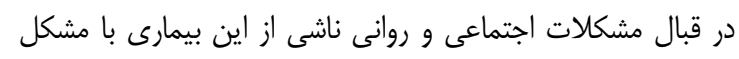

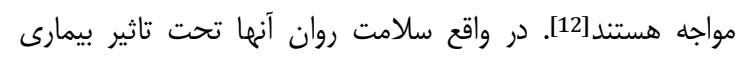

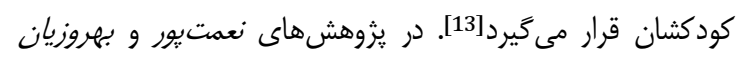

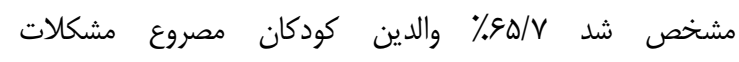

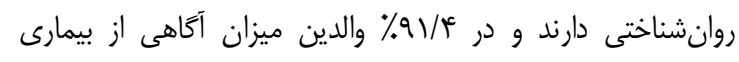

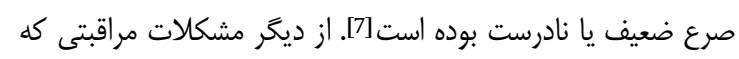

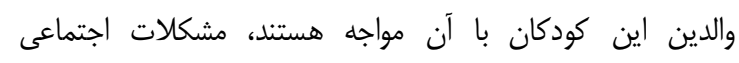

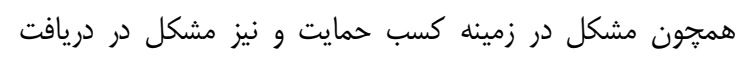

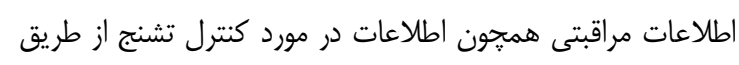
داروهاى مختلف، رزيم غذايى و جراحى است [12].

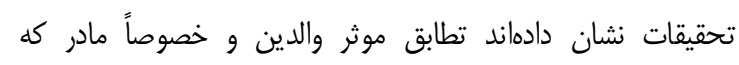

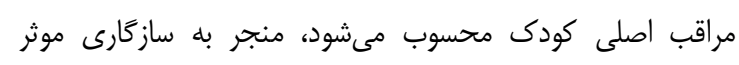

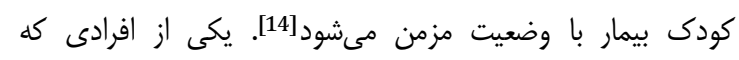

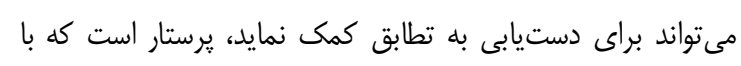

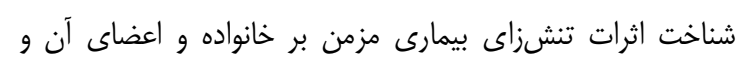

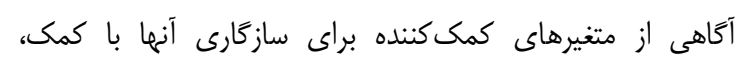

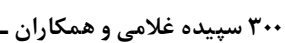

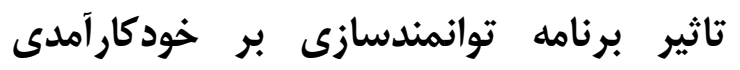

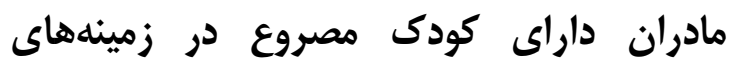
تطابق روانى، كسب حمايت و دريافت اطلاعات

MSc سيبده غلامى

كروه اتاق عمل، دانشكده برستارى و مامايى، دانشكاه علوم بزئشى خراسان شمالى، بجنورد، ايران طيبه ريحانى كروه يرستارى كودى و نوزاد، دانشكده يرستارى و مامايى، دانشخاه علوم يزشكى مشهر، مشهد، ايران

مهران بيرقى طوسى PhD كروه كودكان، دانشكده يزشكى، دانشكاه علوم يز شكى مشهرد، مشهر، ايران حميدرضا بهنام وشانى كروه يرستارى كودى و نوزاد، دانشكده يرستارى و مامايى، دانشخاه علوم يزشكى مشهر، مشهر، ايران

جكيده

اهداف: بيمارى صرع از شايعترين اختلالات عصبى در دوره كودكى

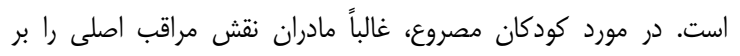

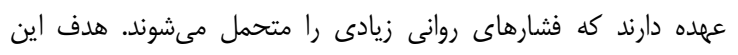

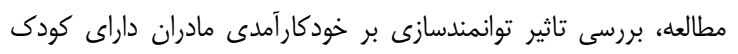

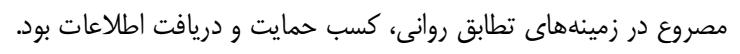

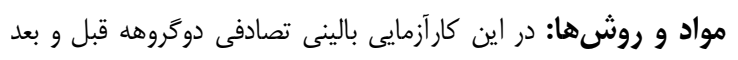

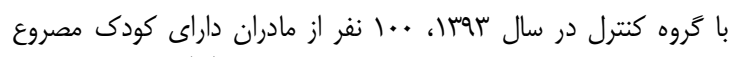

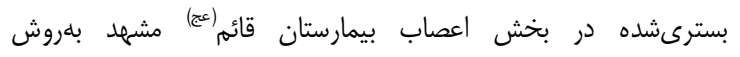

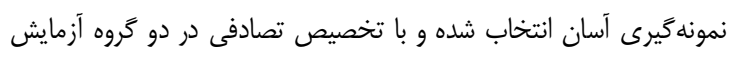

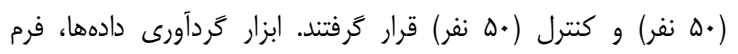

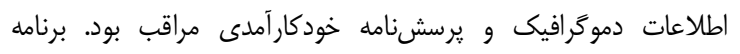

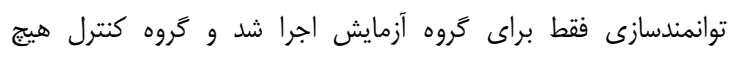

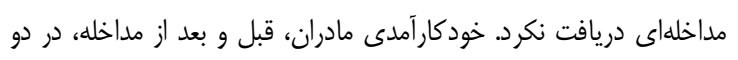

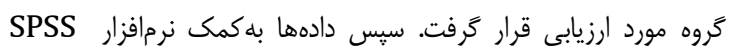

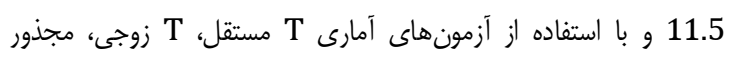

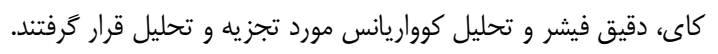

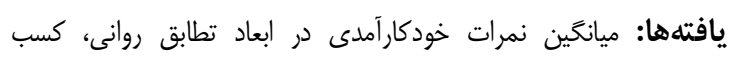

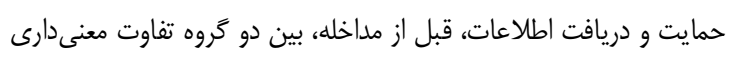

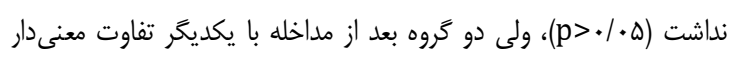

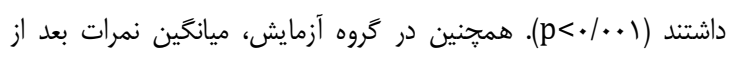

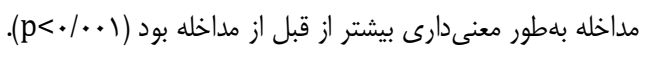

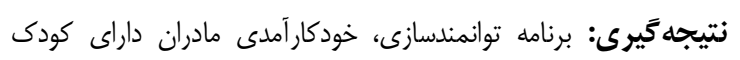

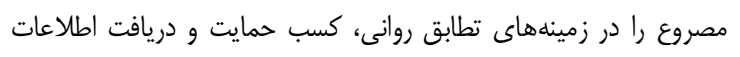
افزايش مى مهدر. كليدوازهها: توانمندسازى، خودكار آمدى، صرع، تطابق روانى، دريافت اطلاعات

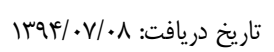

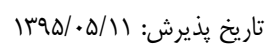

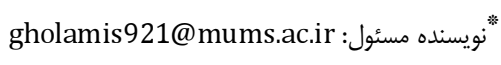

دوره rr، شماره F، پاييز Dوسا

فصلنامه افق دانش 


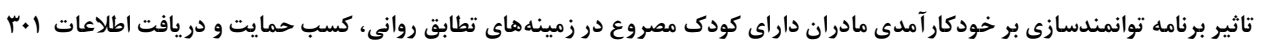

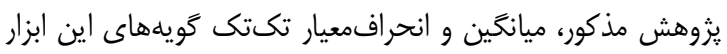

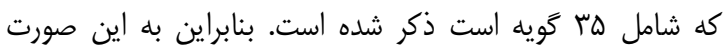

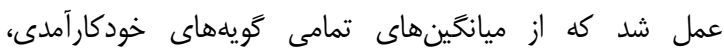

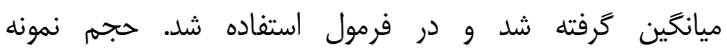

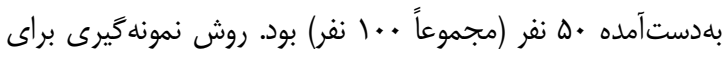

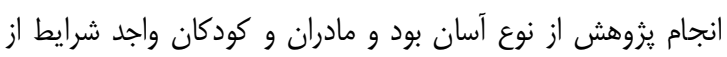

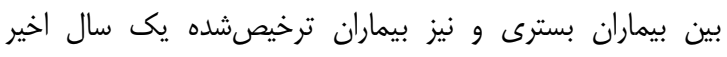

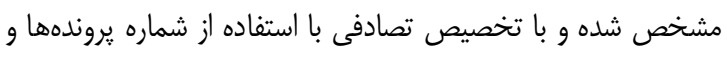

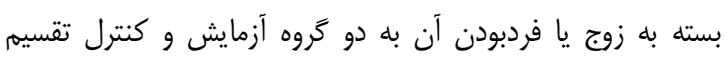
شدند. معيارهاى ورود به مطالعه شامل؛ قرارداشتن كودى در محدوده سنى

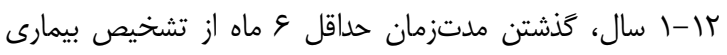

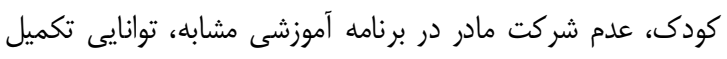

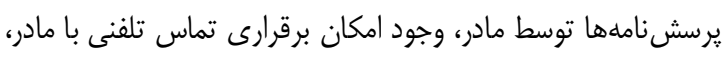

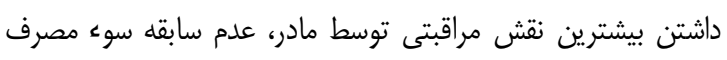

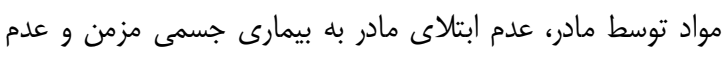

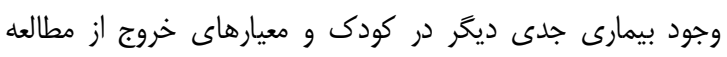

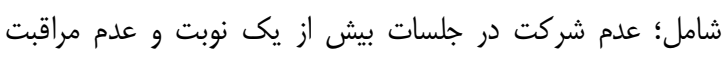

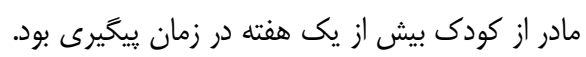

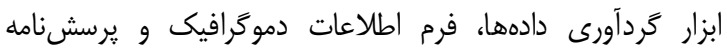

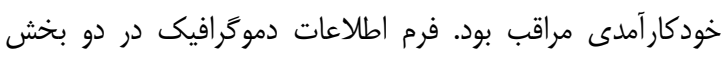

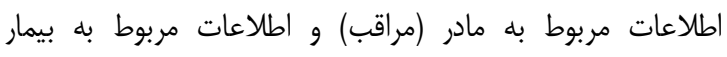

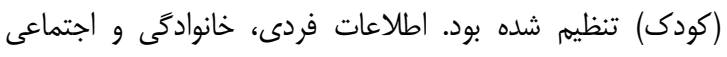

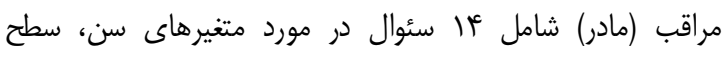

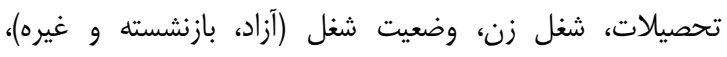

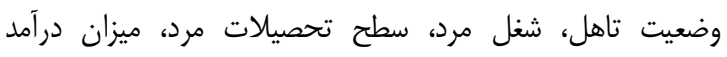

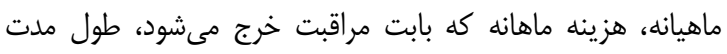

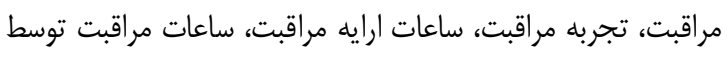

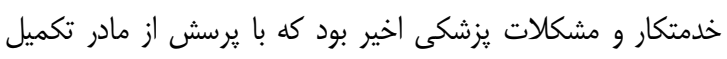

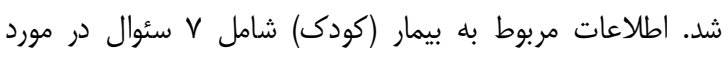

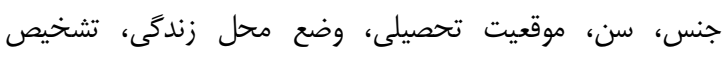

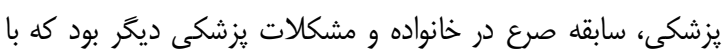

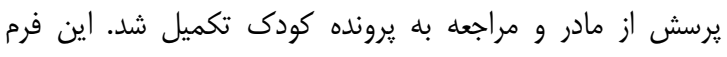

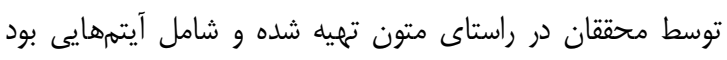

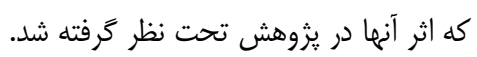

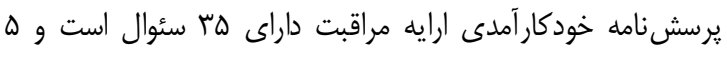

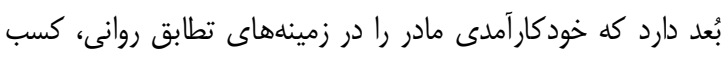

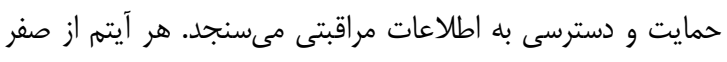

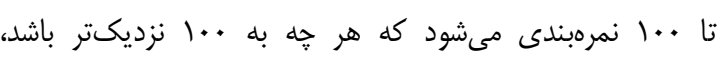

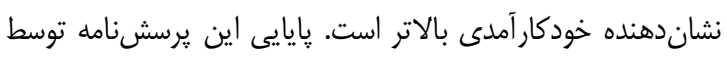

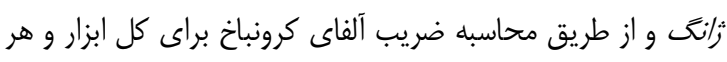

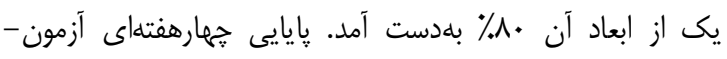

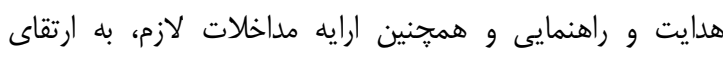

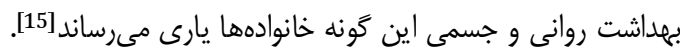

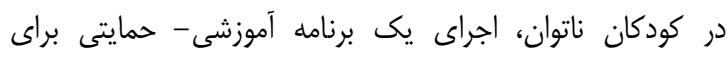

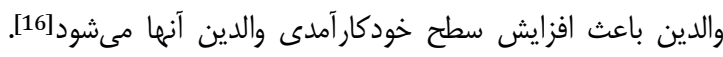

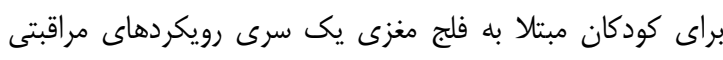

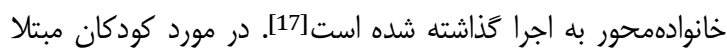

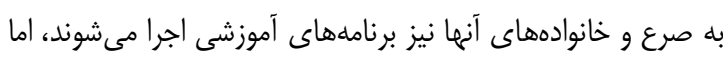

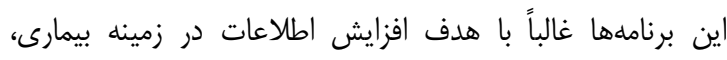

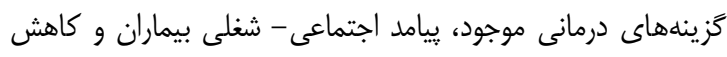
ترسها در مورد بيمارى صورت كَرفته است [18]

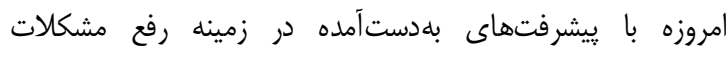

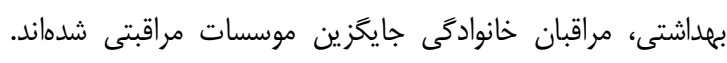

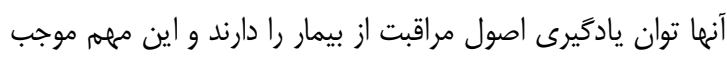

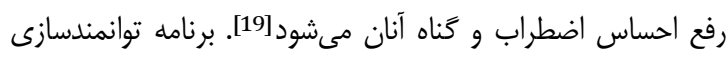

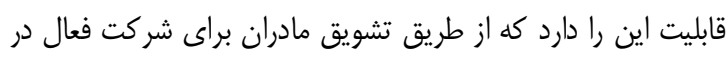

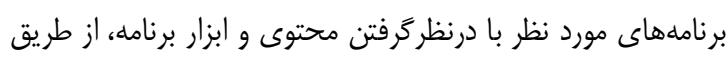

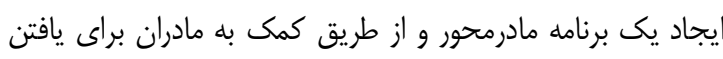

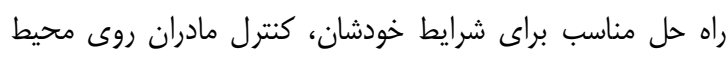
اطرافشان را افزايش دهد [نائ.

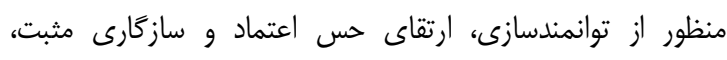

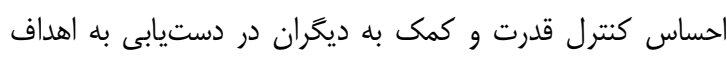

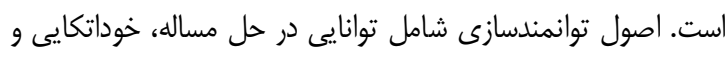

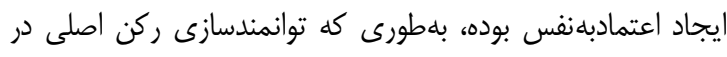

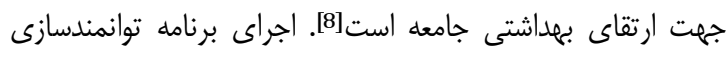

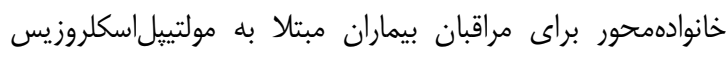

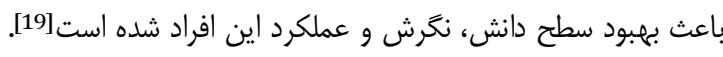

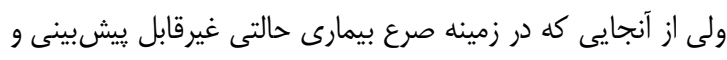

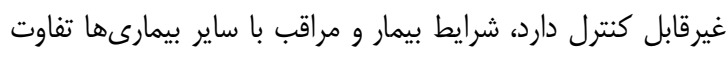

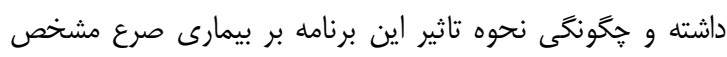
لذا مطالعه حاضر با هدف بررسى تاثير برنامه توانمندسازى بر

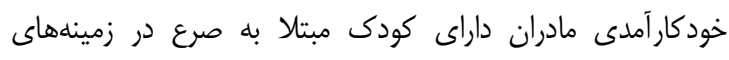
تطابق روانى، كسب حمايت و دريافت اطلاعات انجام شد.

\section{مواد و روش إنها}

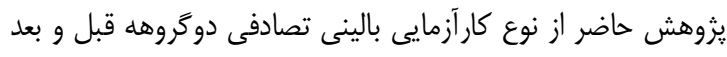

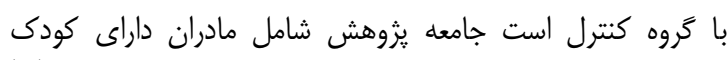

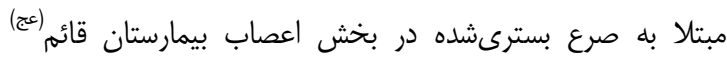

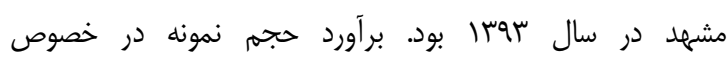

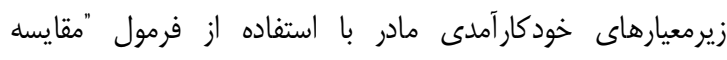

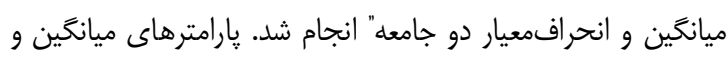

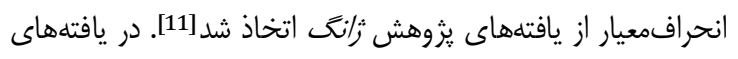


انتخاب راه حلها عملاً مشاركت كردند. همجنين در اين مرحله

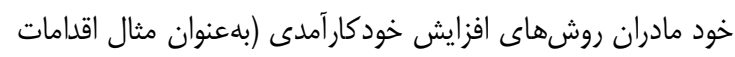

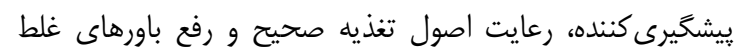

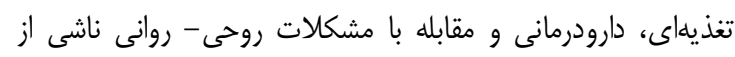

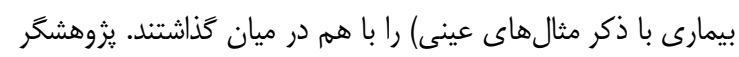

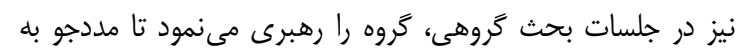

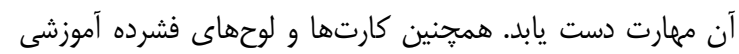

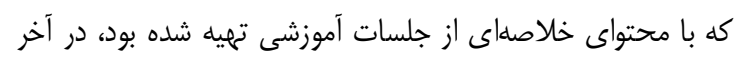

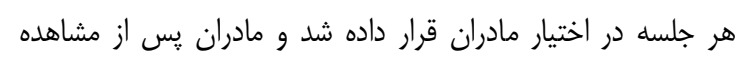

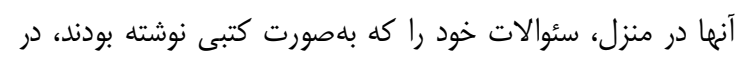

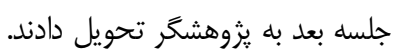

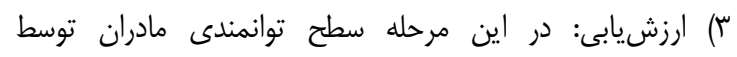

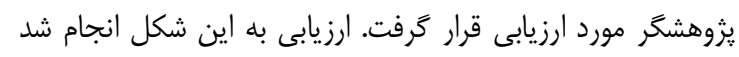

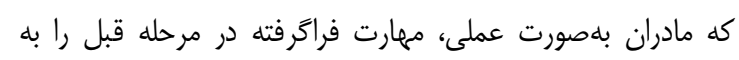

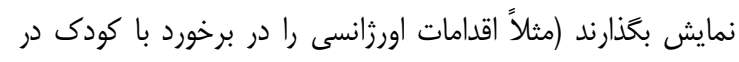

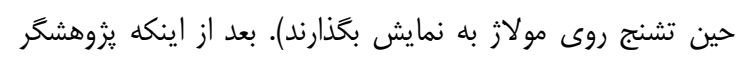

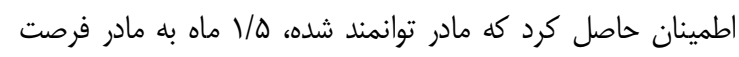

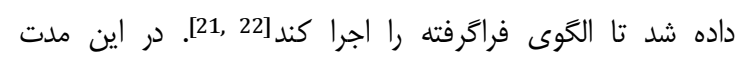

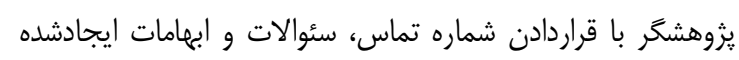

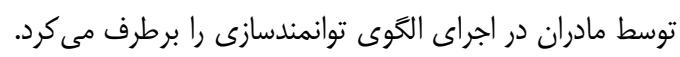

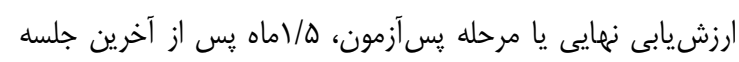

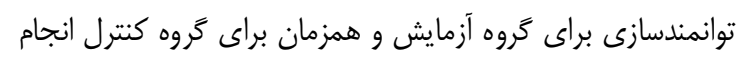

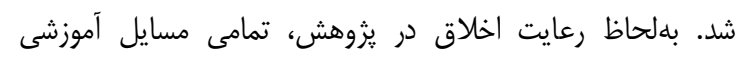

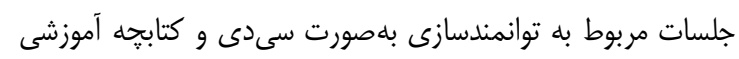
تكثير و در اختيار كروه كنترل قرار كرفت بران.

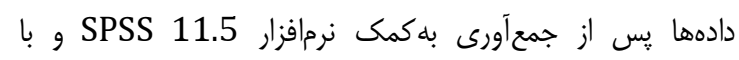

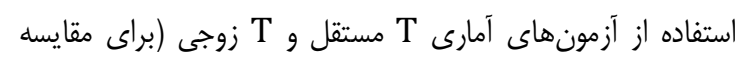

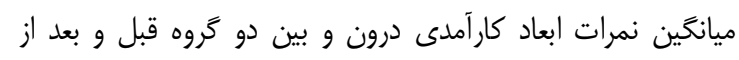

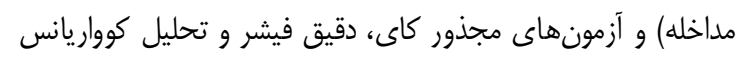

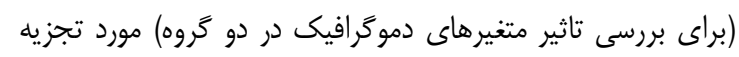
و تحليل قرار گرفت.

يافتهها

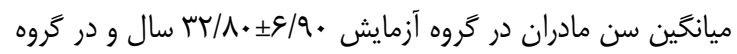

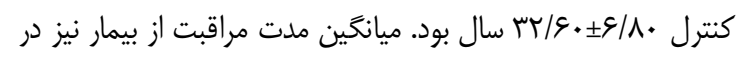
كروه آزمايش • • • • • ماه بود.

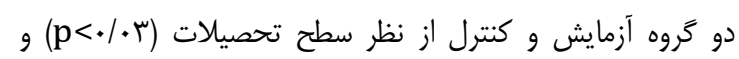

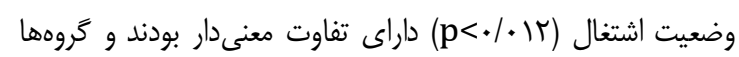

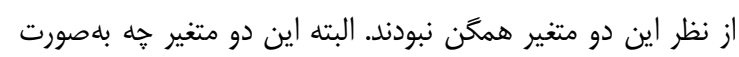

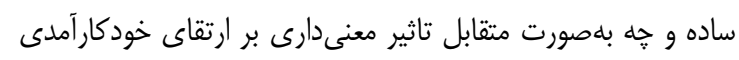

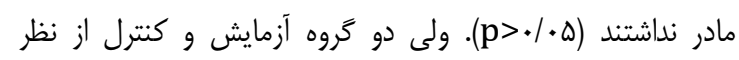

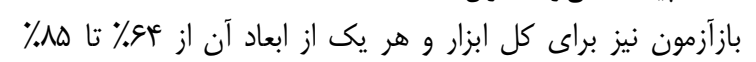

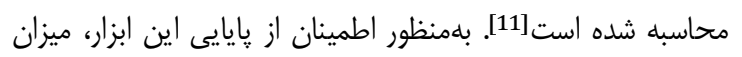

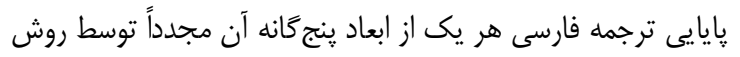

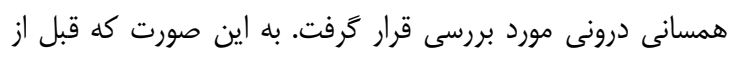

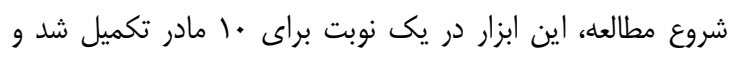

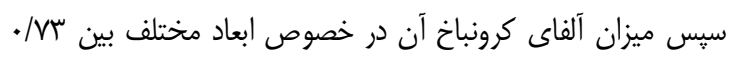

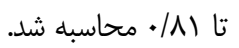
براى تعيين روايى علمى ابزارها، از روايى محتوى استفاده شد و ابزار

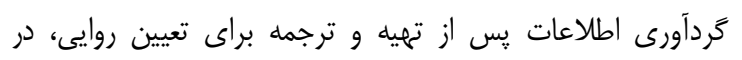

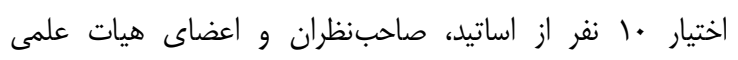

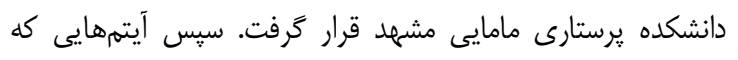

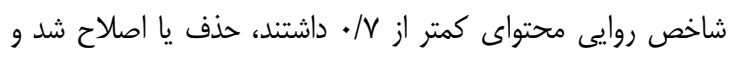

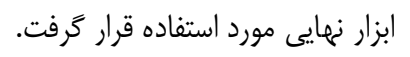

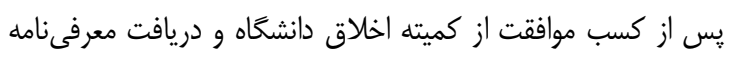

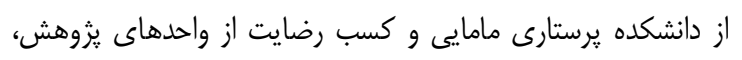

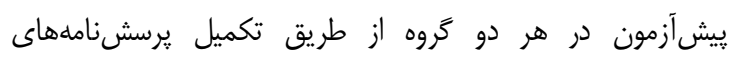

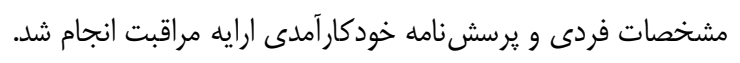

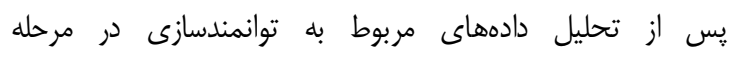
ويشآزمون كه منجر به شناسايى محدوديتها و و نيازها و نقاط نقاط

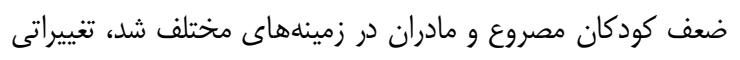

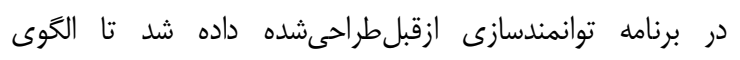

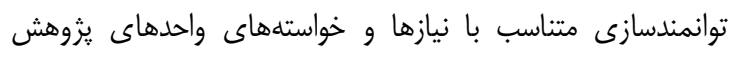

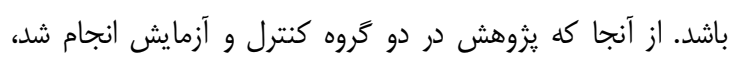

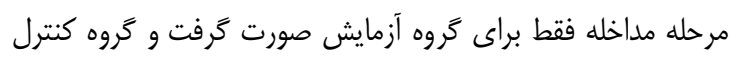
هيج كَونه مداخلهاى دريافت نكرد.

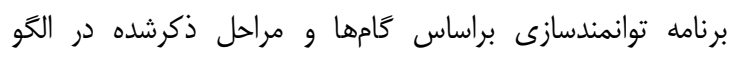

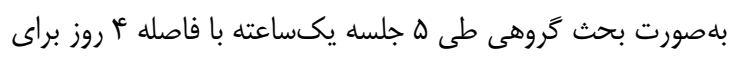
كروه آزمايش به شرح زير انجام شد:

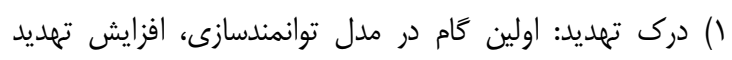

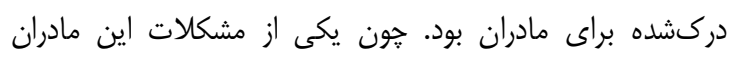

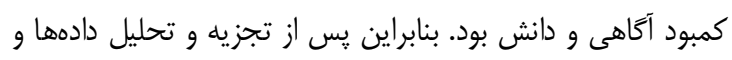

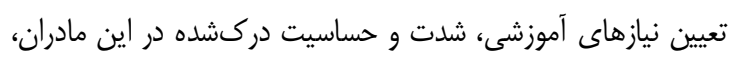

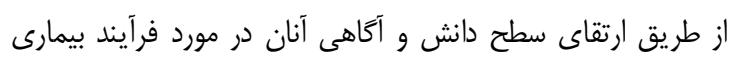

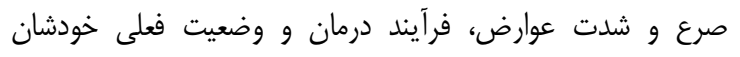
افزايش داده شد.

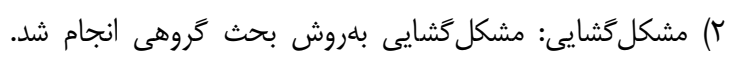

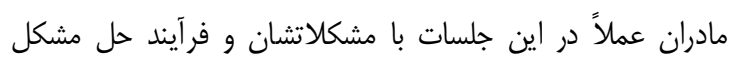

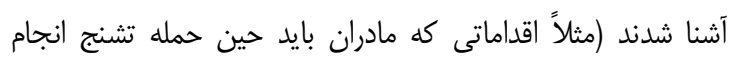

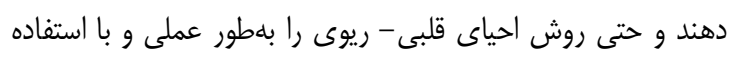

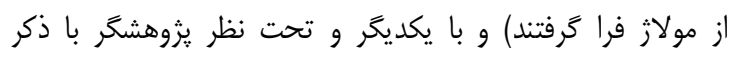

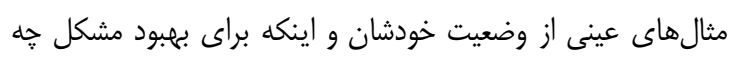

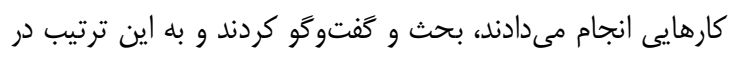




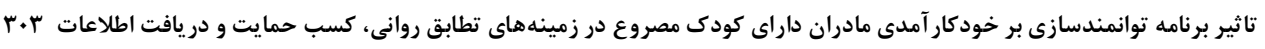

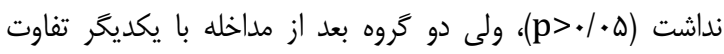

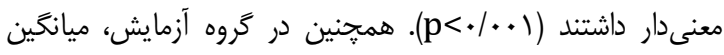

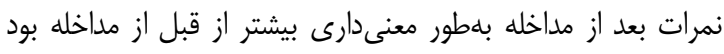

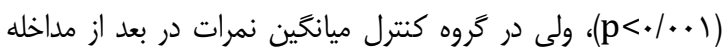

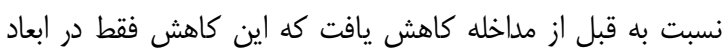

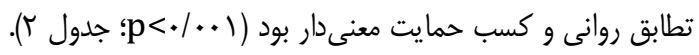

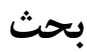

نتايج بزوهش حاضر در زمينه تعيين تاثير برنامه توانمندسازى

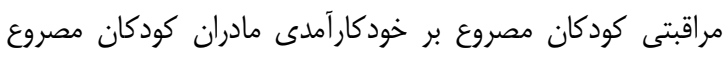

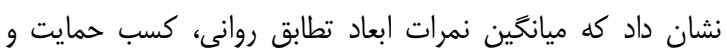

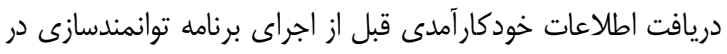

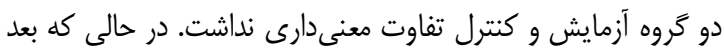

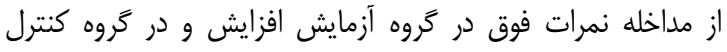

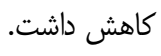

در مطالعاى كه بإفلين و همكاران انجام دادند، به بررسى تاثير

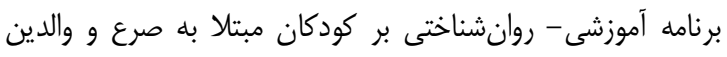

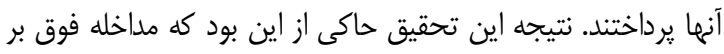

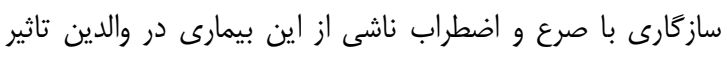

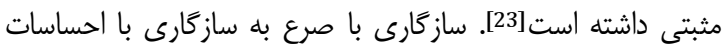

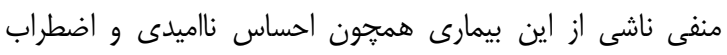

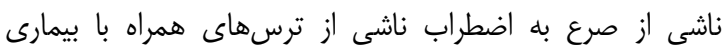

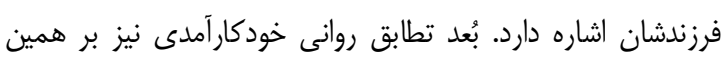

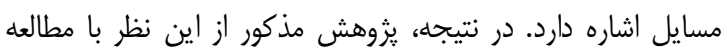

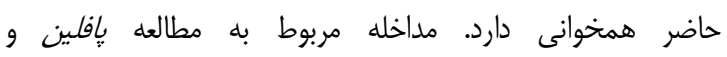

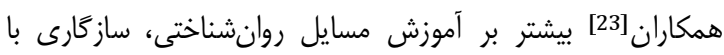

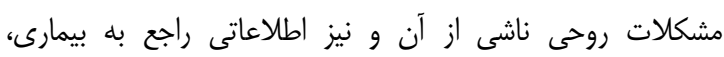

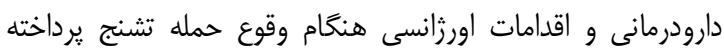

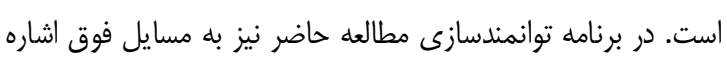

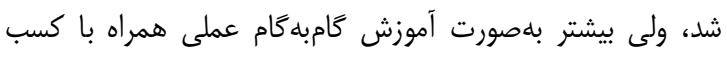

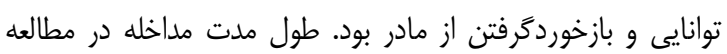

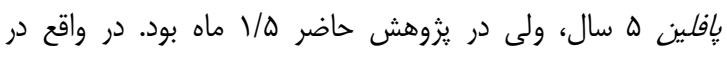

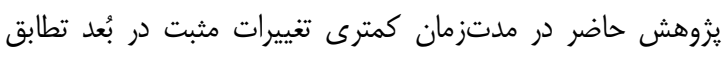

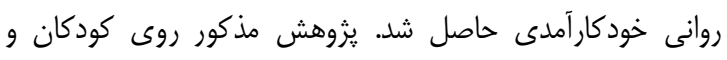

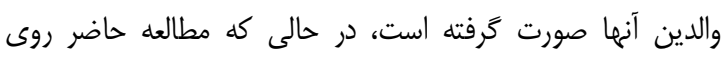

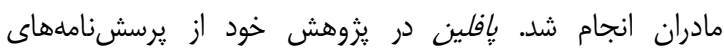

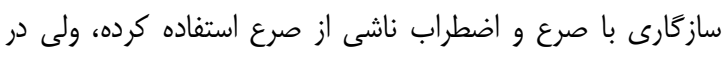

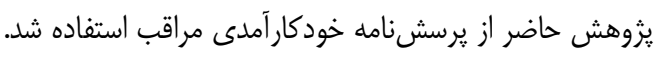

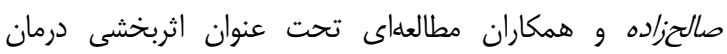

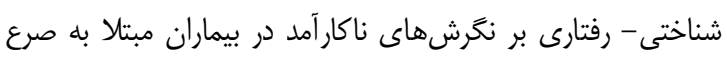

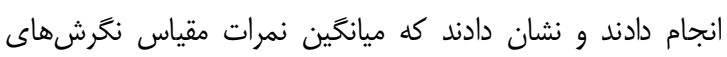

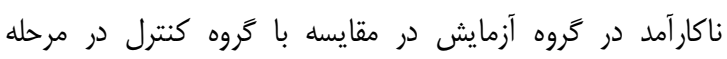

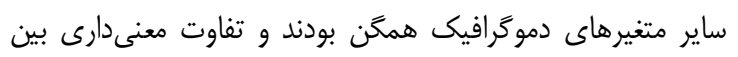

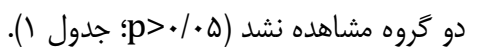

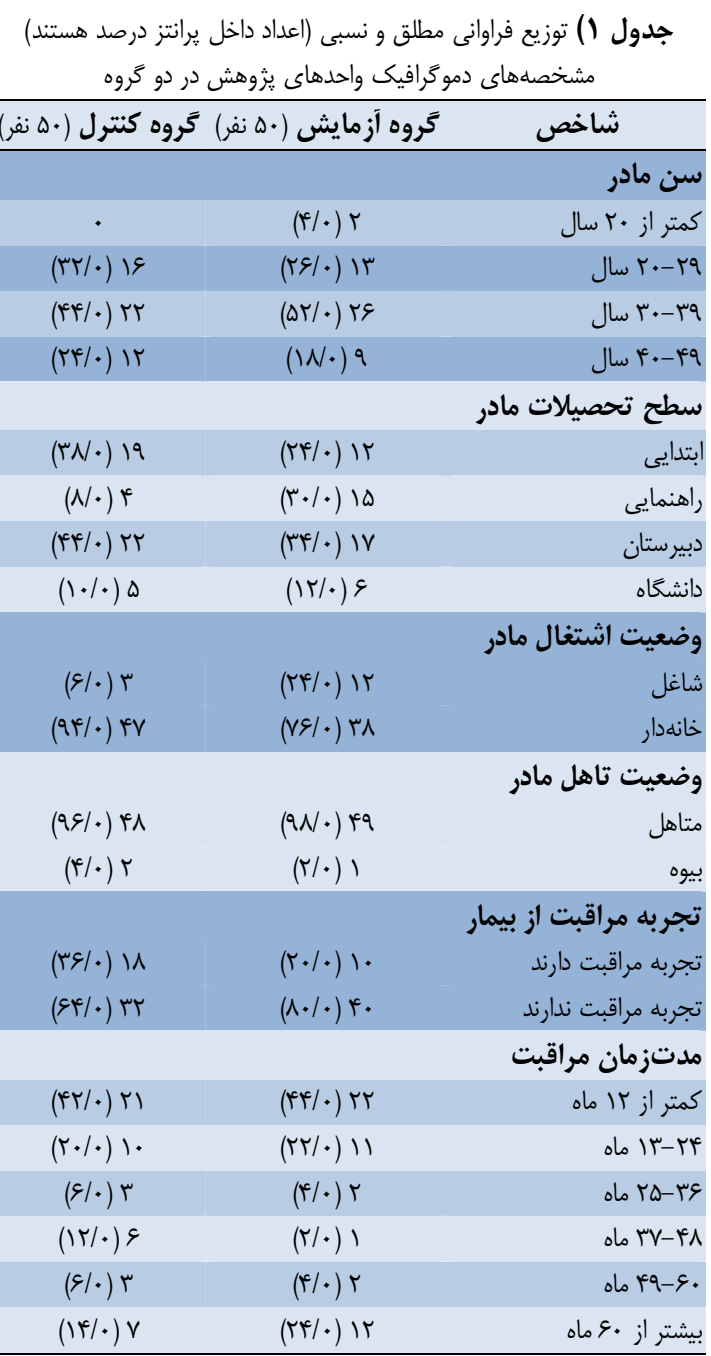

جدول r) مقايسه ميانگين آمارى نمرات ابعاد خودكار آمدى مادران داراى كودى

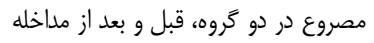

\begin{tabular}{|c|c|c|}
\hline \multicolumn{2}{|c|}{ كَروه آزمايش (•ه نفر) تحروه كنترل (•هنفر) } & \multirow{2}{*}{ بُعد تطابق روانى خودكار آمدى } \\
\hline & & \\
\hline$\kappa q / \Delta \cdot \pm r \pi / 1$. & $\Delta r / V \cdot \pm r I / r$. & قبل از مداخله \\
\hline$r \& / \Lambda \cdot \pm r r / \Lambda$. & $99 / 9 . \pm 1 N / r$. & بعد از مداخله \\
\hline \multirow{3}{*}{$\begin{array}{l}r M / Q \cdot \pm r r / D \cdot \\
r N / V \cdot \pm r \cdot / r .\end{array}$} & & بُعد كسب حمايت \\
\hline & $r r / F \cdot \pm r \mid / \Lambda$. & قبل از مداخله \\
\hline & $F V / r \cdot \pm I N / V$. & بعد از مداخله \\
\hline \multicolumn{3}{|r|}{ بُعد دريافت اطلاعات } \\
\hline$r q / r \cdot \pm r r / \Lambda$. & $r \Delta / \varepsilon \cdot \pm \Gamma r / \varepsilon$. & قبل از مداخله \\
\hline$r V / 1 \cdot \pm r T / V$. & $9 Q / 9 \cdot \pm 19 / 1$. & بعد از مداخله \\
\hline
\end{tabular}

ميانكين نمرات خودكار آمدى در ابعاد تطابق روانى، كسب حمايت و

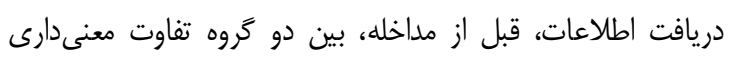


سالمند مبتلا به دمانس صورت گرفت. در مطالعه كووك هر دو

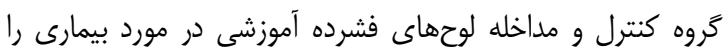

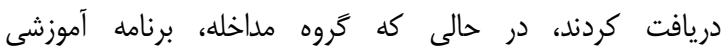
روانشناختى را نيز از طريق تلفن و توسط يك مددكار اجتماعى درى دردي طى זا جلسه دريافت نمودند. در مطالعه حاضر زَروه كنترل مداخله

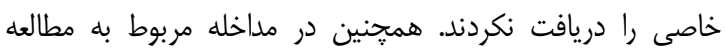
حاضر از ييگيرى تلفنى استفاده شد كه فقط بهمنظور مادران براى اطمينان از اجراى برنامه توانمندسازى بود و مداخله

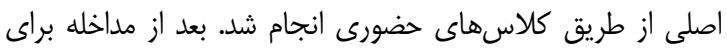

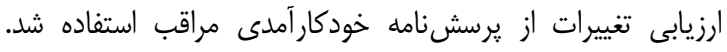
يثوهش مذكور از نظر ابزار با مطالعه حاضر همخوانى دارد. در يزوهش كووى مشخص شد كه برنامه آموزشى روانشناختى باعث

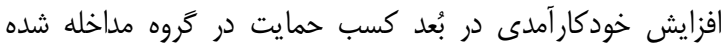

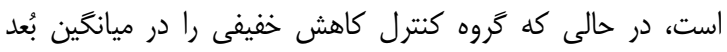

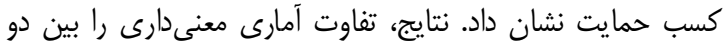

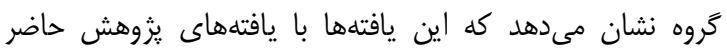
همخوانى دارند. هيرفان/وغلو و همكاران در مطالعه خود نشان دادند كه بين دانش،

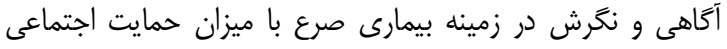
كه كودكان مصروع، والدين و خواهر و برادر آنها كسب مئى كنيند رابطه مثبتى برقرار است[28]. از آنجا كه مداخله صورت وكرفته در يثوهش حاضر نيز باعث بهبود دانش، آكاهى و نخَرش مادران

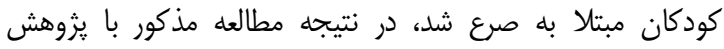

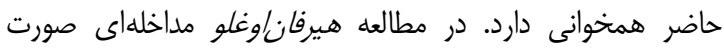

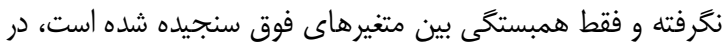
حالى كه در يزوهش حاضر مداخله توانمندسازى صورت كرفت.

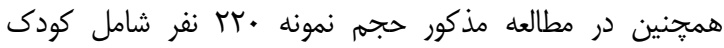
مصروع، والدين و خواهر و برادرهاى او بوده است.

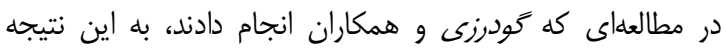

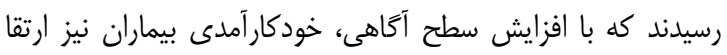
مىيابد[29]. از آنجا كه انتظار مىرود در بئى برنامه توانمندسازى آنى

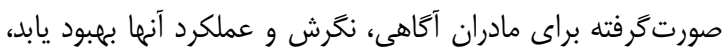
بنابراين حتى با وجود برخى تفاوتها، نتيجه حاصل از مطالعه

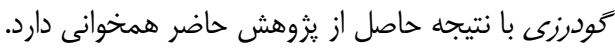

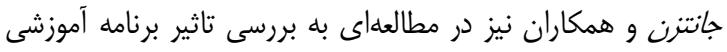

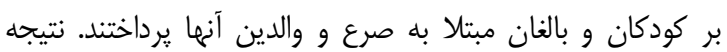

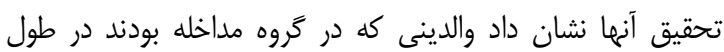

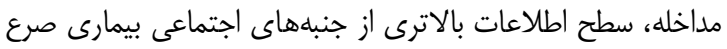

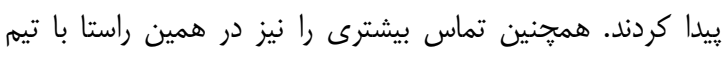

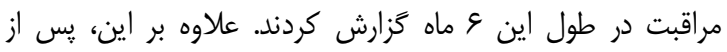
مداخله مهارتهاى خودمديريتى و ارتباطى نيز در اين والدين

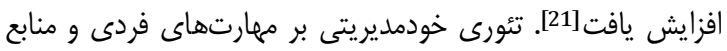

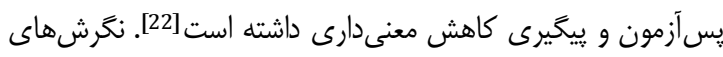

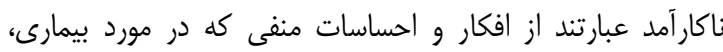

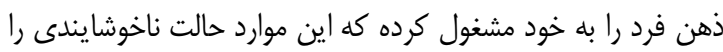

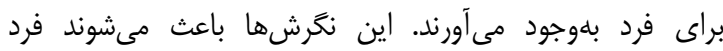

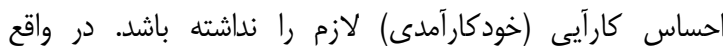
نخرشهاى ناكارآمد نقطه مقابل خودكارآمدى هستند. در نتيجه،

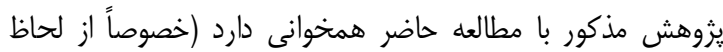
بهبود خودكارآمدى در بُعد تعديل حالت روانى ناشى از مدانى بيمارى

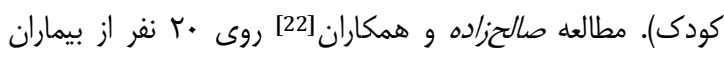

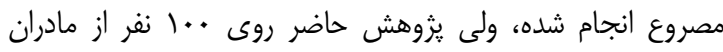
كودكان مصروع صورت گرفت. با توجه به بيشتربودن حجم نمونس نمونه

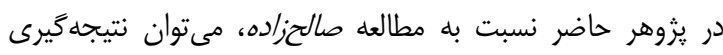

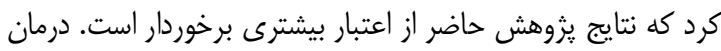

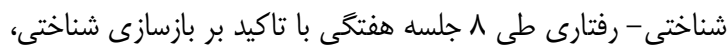

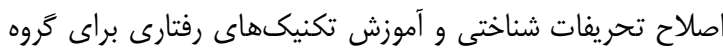

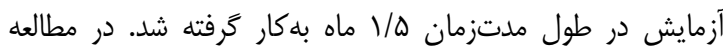
حاضر بعد از ه جلسه توانمندسازى (در مدتزمان كمترى) نتايج مثبت حاصل شد.

لطفى كاشانى يزوهشى را بلمنظور بررسى تاثير گروهدرمانى با

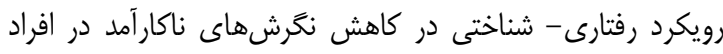

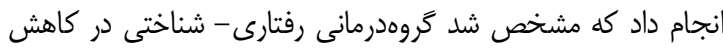

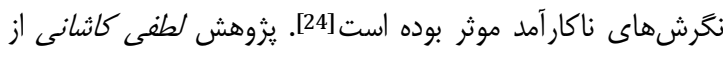

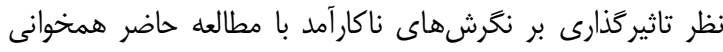

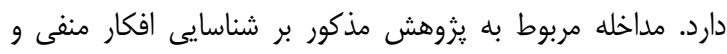

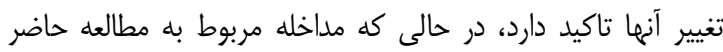

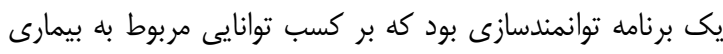

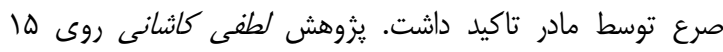

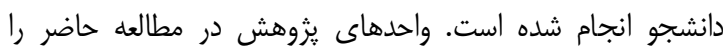

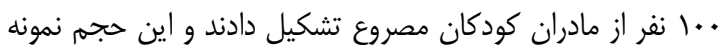
بالاتر باعث شده كه مطالعه حاضر از اعتبار بيشترى برخوردار باشد.

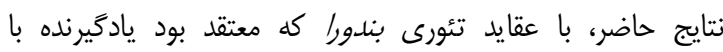

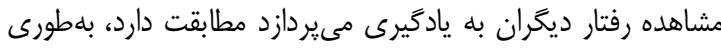

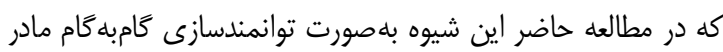

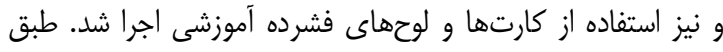

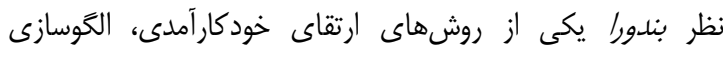
اجتماعى است. الخوسازى به حالتى اشاره دارد كه فرد با مشاهده

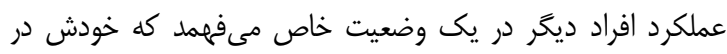

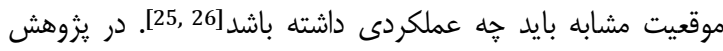
حاضر از اين روش در برنامه توانمندسازى استفاده شد.

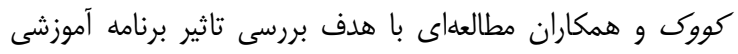
روانشناختى تلفنى بر مراقبان بيماران مبتالا به دمانس هينى هارئ ساكن

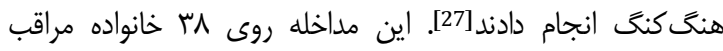




\section{منابع}

1- Mahrer-Imhofa R, Jaggib S, Bonomoc A, Hedigera $H$, Eggenschwilerc P, Kramerc G, et al. Quality of life in adult patients with epilepsy and their family members. Seizure. 2013;22(2):128-35.

2- Readinga R, Haynes BR, Beach CR. Deprivation and incidence of epilepsy in children. Seizure. 2006;15(3):190-3.

3- Aliasgharpour M, Dehgahn Nayeri N, Yadegary M, Haghani $H$. Effects of an educational program on selfmanagement in patients with epilepsy. Seizure. 2013;22(1):48-52.

4- Cole C, Pointu A, Mahadeshwar S, Dudley A. Community survey of carer's: Individual epilepsy guidelines (IEG) for rescue medication. Seizure. 2009;18(3):220-4.

5- Kaheni S, Rezvani Khorashad MR, Sharefzadeh GR, Nakhaee S. Incidence of epilepsia in school age childerens and teachers knowledge in Birjand elementary schools. Mod Care J. 2011;8(3):135-42. [Persian]

6- Akay AP, Hiz Kurul S, Ozek H, Cengizhan S, Emiroglu N, Ellidokus H. Maternal reaction to a child with epilepsy: Depression, anxiety, parentral attitudes and family functions. Epilepsy Res. 2011;95(3):213-20.

7- Bastani F, Ghasemi E, Negarandeh R, Haghani H. General self-efficacy among family's female caregiver of elderly with alzheimer's disease. Hayat. 2012;18(2):2737. [Persian]

8- Au A, Lau KM, Sit E, Cheung G, MPhil MKL, Wong SKA, et al. The role of self-efficacy in the Alzheimer's family caregiver stress process: A partial mediator between physical health and depressive. Clin Geront. 2010;33(4):298-315.

9- Singh B, Udainiya R. Self-efficacy and well-being of adolescents. J Indian Acad Appl Psychol. 2009;35(2):22732 .

10- Kara M, van der Bijl JJ, Shortridge-Baggett LM, Asti T, Erguney S. Cross-cultural adaptation of the diabetes management self-efficacy scale for patient with type 2 diabetes mellitus: Scale development. Int J Nurs Stud. 2006;43(5):611-21.

11- Zhang SY. Measurement and correlates of caregiver self-efficacy amongst family caregivers of persons with dementia living in Shanghai, China [Dissertation]. Shanghai: Zhejiang University; 2010.

12- Farnalls S, Rennick J. Parents' caregiving approaches: Facing a new treatment alternative in severe intractable childhood epilepsy. Seizure. 2003;12(1):1-10.

13- Sadock BJ, Sadock VA. Kaplan and Sadock`s synopsis of psychiatry. Philadelphia: Lippincott Williams \& Wlkins; 2007.

14- Mahab R, Ebrahimi Moghadam H, Mirhashemi M. Investigate difference between girls and boys aged 6-12 with Epilepsy In respect to symptom. Int J Pharm Therap. 2013;4(4):261-4.

15- Taghavi Larijani T, Sharifi N, Mehran A, Nazari S. Level of coping with stressors in parents of epileptic children. Hayat. 2006;12(2):63-71. [Persian]

16- Barlow J, Powell L, Gilchrist M. The influence of the training and support programme on the self-efficacy and psychological well-being of parents of children with disabilities: A controlled trial. Complement Ther Clin Pract. 2006;12(1):55-63.

17- KiKing S, Teplicky R, King G, Rosenbaum P. Family-
لازم براى مديريتكردن يك بيمارى مزمن در متن زندگى روزئ رومره

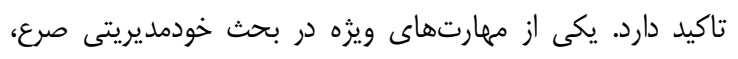
خودكارآمدى در اداره تشنج است. بنابراين يافتههاى مطالعه جانتنرن

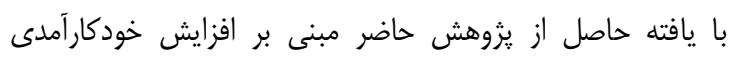

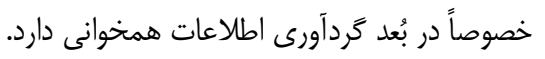

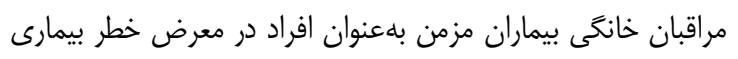

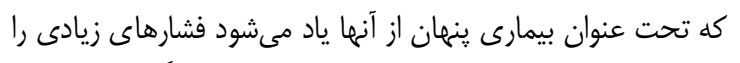

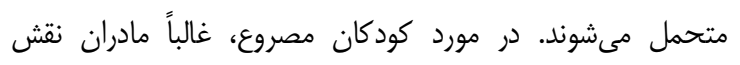

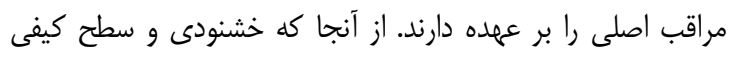
زندگى در اين افراد كه بيماران آنها در سنين مولد و زاياى زندأنى إنى

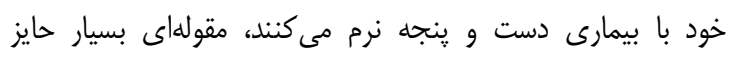

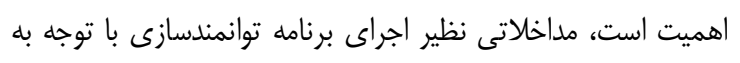

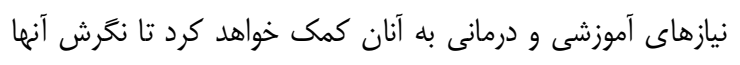

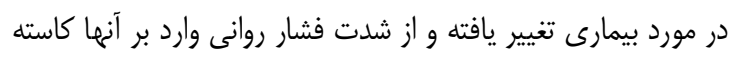

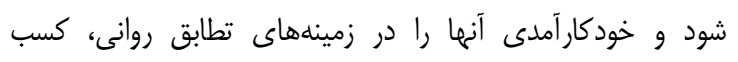

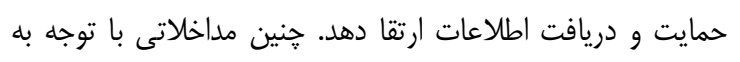

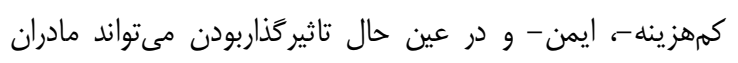

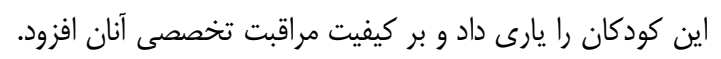

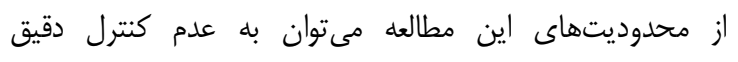

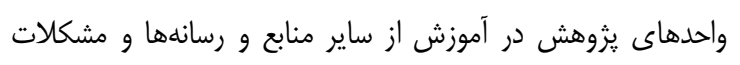

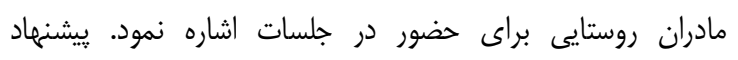

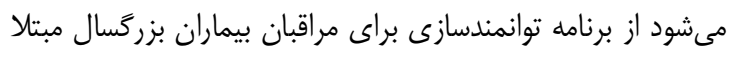

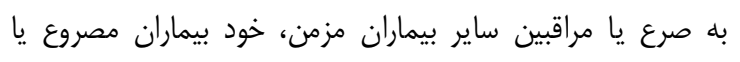
توانمندسازى خانوادهمحور بيماران مصروع استفاده شود.

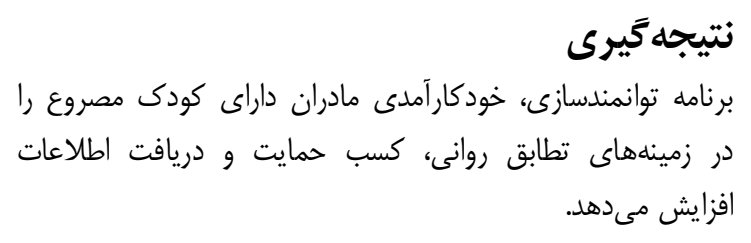

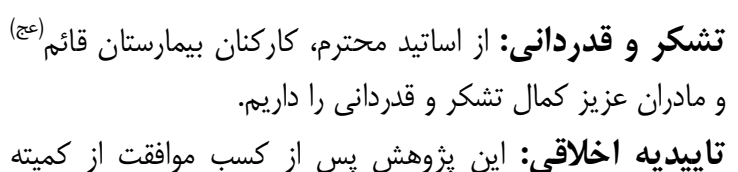

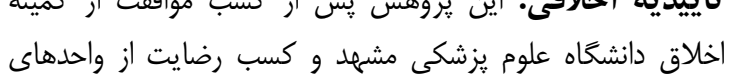

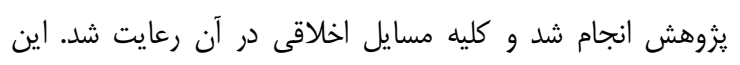

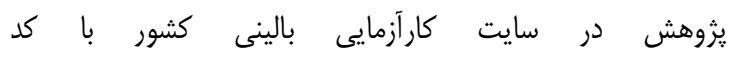
IRCT2015012720827N1

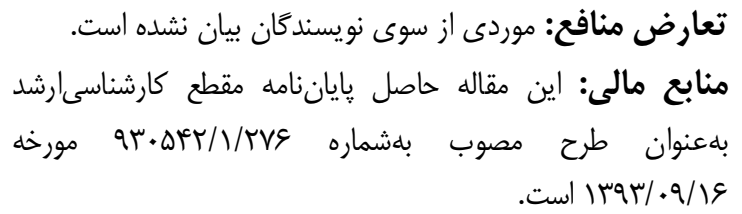


24- Lotfi Kashani F. The effect of group counseling with regard to cognitive- behavioral approach on the decrease of dysfunctional attitude. Andisheh va Raftar. 2008;8(2):67-78. [Persian]

25- Heidari A, Emami moghaddam Z, Ebrahim zade S, Dashtgerd A. The effect of Applying Bandura's socialcognitive theory on addiction quitting in clients referred to clinic of addiction quitting at Imam Reza hospital of Mashhad [Dissertation]. Mashhad: Mashhad School of Nursing and Midwifery; 2009. [Persian]

26- Soleimani E, Hoveida R. Bandura's social cognitive theory of self-study. Soc Sci J. 2012;63(17):91-7. [Persian]

27- Kwok T, Wong B, Chui K, Young D, Ho F. Telephonedelivered psychoeducational intervention for Hong Kong Chinese dementia caregivers: A single-blinded randomized controlled trial. Clin Int Aging. 2013;8:1191-7. 28- Hirfanoglu T, Serdaroglu A, Cansu A, Soysal S, Derle E, Gucuyener K. Do knowledge of, perception of, and attitudes toward epilepsy affect the quality of life of Turkish children with epilepsy and their parents? Epilepsy Behav. 2009;14(1):71-7.

29- Godarzi M, Ebrahimzadeh E, Rabie A, Saedipur B, Asgharigafarabadi M. Evaluation of relationship between knowledge, perception and attitudes with self-efficacy of diabetics patients in Karaj. Iran J Diabetes Lipid Disorders. 2012;11(3):269-81. [Persian]

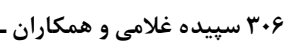

centered service for children with cerebral palsy and their families: A review of the literature. Semin Pediatr Neurol. 2014;11(1):78-86.

18- Wohlrab GC, Rinnert S, Bettendorf U, Fischbach H, Heinen G, Klein P, et al. Famoses: A modular educational program for children with epilepsy and their parents. Epilepsy Behav. 2007;10(1):44-8.

19- Masoodi R, Alhani F, Moghadassi J, Ghorbani M. The effect of family-centered empowerment model on skill, attitude, and knowledge of multiple sclerosis caregivers. J Birjand Univ Med Sci. 2010;17(2):87-97. [Persian]

20- Kang JS, Choi SY, Ryu EJ. Effects of a breastfeeding mothers: A quasi-experimental study. Int J Nurs Stud. 2008;45(1):14-23.

21- Jantzen S, Muller-Godeffory E, Hallfahrt-Krisl T, Aksu F, Pust B, Konl B, et al. FLIP\&FLAP-A training programme for children and adolescents with epilepsy and their parents. Seizure. 2009;18(7):478-89.

22- Salehzadeh M, Najafi M, Ebrahimi A. Effectiveness of cognitive-behavioral therapy on dysfunctional attitudes in epileptic patients. J Shahid Sadoughi Univ Med Sci. 2011;19(3):377-87. [Persian]

23- Pfäfflin M, Petermann F, Rau J, May TW. The psychoeducational program for children with epilepsy and their parents (FAMOSES): Results of a controlled pilot study and a survey of parent satisfaction over a five-year period. Epilepsy Behav. 2012;25(1):11-6. 